\title{
Platelet-Derived Growth Factor Receptor
}

National Cancer Institute

\section{Source}

National Cancer Institute. Platelet-Derived Growth Factor Receptor. NCI Thesaurus.

Code C17322.

A cell surface protein that has tyrosine-kinase activity. This receptor specifically binds to platelet derived growth factor, and its analogs and antagonists. Lig and binding causes homodimerization or heterodimerization, resulting in receptor activation. 